\title{
TINJAUAN PELAKSANAAN PENYUSUTAN BERKAS REKAM MEDIS INAKTIF DI RUMAH SAKIT KHUSUS JIWA SOEPRAPTO BENGKULU
}

\author{
Yoki Hermansyah \\ Prodi D3 Rekam Medis dan Informasi Kesehatan \\ Akademi Kesehatan Sapta Bakti Bengkulu
}

\begin{abstract}
Abstrak
Berdasarkan observasi secara langsung di Rumah Sakit Khusus Jiwa Soeprapto Bengkulu Berkas rekam medis telah banyak yang menumpuk di rak filling, sehingga dilakukan penyusutan dan akan melakukan pemusnahan berkas rekam medis inaktif.Tujuan penelitian ini adalah untuk mengetahui Gambaran Pelaksanaan Penyusutan Berkas Rekam Medis Inaktif Di Rumah Sakit Khusus Jiwa Soeprapto Bengkulu. Jenis penelitian yang digunakan adalah Deskriptif, Populasi dalam penelitian ini yaitu 1000 Berkas Rekam Medis Inaktif di, sampel sebanyak 285 BRM Inaktif dengan teknik pengambilan Non Probality sampling dengan jenis Consecutive sampling. Menggunakan data sekunder, diolah secara univariat. Penelitian dilaksanakan bulan Januari Tahun 2016 di Rumah Sakit Khusus Jiwa Soeprapto Bengkulu, bertempat di ruang penyimpanan berkas rekam medis aktif dan inaktif. Hasil Penelitian, dari jumlah sampel yaitu 285 berkas rekam medis didapat 54 (18,9\%) yang belum bisa disusutkan dan $231(81,1 \%)$ sudah siap disusutkan karena jangka waktu nya sudah lebih dari 15 tahun. Pelaksanaan Persiapan prosedur pemusnahan belum sesuai karena tata cara nya belum terlaksana semua seperti pembentukan tim penilai dan pembuatan berita acara pemusnahan. Diharapkan SOP penyusutan di revisi, tersedia jadwal penyusutan, tersedia ruangan penyimpanan inaktif permanen, segera lengkapi persiapan pembuatan tim pemusnah dan berita acara pemusnahan, serta melakukan pemusnahan berkas inaktif yang tidak bernilai guna.
\end{abstract}

Kata Kunci : : Berkas Rekam Medis, Inaktif, Penyusutan

\section{PENDAHULUAN}

Berdasarkan Undang-Undang No. 44 tahun 2009 tentang rumah sakit, yang dimaksudkan dengan rumah sakit adalah institusi pelayanan kesehatan perorangan secara paripurna yang menyediakan pelayanan rawat inap, rawat jalan, dan gawat darurat. Rumah sakit wajib mengadakan pelayanan rekam medis.

Rekam Medis adalah berkas yang berisi catatan dan dokumen tentang identitas pasien, pemeriksaan, pengobatan, tindakan dan pelayanan lain kepada pasien pada fasilitas pelayanan kesehatan (Permenkes 55, 2013).
Berkas rekam medis berisi data individual yang bersifat rahasia, maka setiap lembar formulir berkas rekam medis harus dilindungi dengan cara dimasukkan ke dalam folder atau map (Budi, 2011). Untuk itu berkas harus disimpan di rak penyimpanan agar menghindari juga terjadi nya berkas yang rusak, karena semakin banyak nya pasien berobat maka semakin banyak pula berkas rekam medis tersebut. Dengan itu perlu adanya penyusutan/retensi berkas rekam medis agar mengurangi berkas berkas rekam medis yang bertumpuk.

Penyusutan/Retensi adalah suatu kegiatan pengurangan arsip dari rak penyimpanan dengan 
cara memindahkan arsip rekam medis inaktif Dari rak aktif ke rak inaktif dengan cara memilah pada rak penyimpanan sesuai dengan tahun kunjungan terakhir, memikrofilmisasi berkas rekam medis inaktif sesuai ketentuan yang berlaku memusnahkan berkas rekam medis yang telah dimikrofilm dengan cara tertentu sesuai ketentuan, membuat berita acara, pemindahan dan pelaksanaan pemusnahan arsip dilakukan setelah mendapatkan persetujuan pimpinan untuk kerja (Depkes RI, 1997).

Berkas rekam medis dikatakan aktif ketika tanggal pulang atau tanggal kunjungan terakhir masih dalam jangka waktu sepuluh tahun dari tanggal sekarang. Berkas rekam medis dikatakan inaktif ketika rekam medis tersebut jarang diambil dan disimpan kembali. Oleh karena itu, file-file rekam medis inaktif disimpan di tempat yang jarang diakses dari pada rekam medis yang masih aktif (Skurla, 2003)

Adanya kegiatan penyusutan dokumen rekam medis, akan dapat diketahui berkas rekam medis yang masih aktif dan inaktif berdasarkan prosedur tetap yang berlaku di rumah sakit. Dengan demikian, kerapian penataan berkas rekam medis aktif dan inaktif akan dapat membantu petugas rekam medis, khususnya petugas filling dalam pengambilan berkas rekam medis. Penyusutan berkas rekam medis di lakukan dengan bertahap, yaitu mulai dari pemilahan dan pemindahan berkas rekam medis dilihat dari tanggal kunjungan terakhir, setelah 10 tahun dari kunjungan tersebut berkas dipisahkan diruang lain/terpisah dari rekam medis, rekam medis inaktif dikelompokkan sesuai dengan tahun terakhir kunjungan kemudian melakukan penilaian berkas rekam medis dengan cara berkas rekam medis yang telah 5 tahun inaktif, indikator yang digunakan dalam menilai rekam medis inaktif adalah rekam medis sering digunakan untuk pendidikan dan penelitian dengan nilai gunanya yaitu administrasi, hukum, keuangan, Iptek, pembuktian, sejarah (Akasah, 2008)

Menurut Ita Meimoniesha (2016) adanya masalah tentang dokumen rekam medis di RSUD Ambarawa dibagian filling yang semakin hari semakin bertambah dan tidak memungkinkan untuk dimasukkan ke dalam rak filling yang nantinya akan mengakibatkan rak penuh sehingga menumpuknya dokumen rekam medis di rak filling aktif. Hal tersebut, menyebabkan beberapa map dokumen rekam medis sobek dan sulit dilacak. Pelaksanaan retensi di RSUD Ambarawa sudah berjalan dengan baik, tetapi dalam tata cara pelaksanaanya belum sesuai dengan Kebijakan nya. Kesulitan dalam melaksanakan retensi adalah prosedur dan metodenya.

Berdasarkan pengalaman praktik kerja lapangan yang penulis lakukan di RSUD dr. M. Yunus Bengkulu dan Rumah Sakit Rafflesia Bengkulu didapatkan belum adanya pelaksanaan Penyusutan berkas rekam medis inaktif, berkas yang inaktif masih ditumpuk atau diletakkan didalam kardus didekat berkas rekam medis yang aktif, sedangkan di Rumah Sakit Umum Daerah Muntilan Magelang sudah dilaksanakannya sekitar $20 \%$ Penyusutan berkas rekam medis inaktif.

Rumah sakit jiwa berdiri pada tahun 1981 dan di resmikan pada 10 juli 1989, dengan petugas rekam medis berjumlah 15 orang yang 4 orang berkualifikasi rekam medis. Alasan penulis mengambil penelitian di rumah sakit ini yaitu karena penyusutan berkas rekam medis sudah dilakukan pada tahun 1996 tetapi pada tahun selanjutnya belum dilakukan penyusutan kembali dan tahun ini baru akan dilakukan nya penyusutan. Padahal seharusnya penyusutan 
berkas rekam medis jiwa yaitu masa aktifnya selama 10 tahun. Disimpan aktif dari 1 sampai 10 tahun, kemudian 10 sampai 15 nya untuk inaktif dan untuk seperti kasus-kasus hukum masa nya selama 20 tahun seperti kasus pembunuhan, pemerkosaan, dan sebagainya.

Berdasarkan pengamatan pada saat pra penelitian di Rumah sakit khusus jiwa Soeprapto Bengkulu memiliki satu ruangan filling/tempat penyimpanan berkas rekam medis aktif dan satu ruangan penyimpanan berkas rekam medis inaktif. Berkas rekam medis tersebut telah banyak yang menumpuk di rak filling, sehingga berkas rekam medis yang inaktif banyak yang ditumpuk dan diletakkan didekat berkas rekam medis yang aktif. Pertimbangan dalam melaksanakan penyusutan/retensi adalah Standar Operasional Prosedur (SOP), tata cara penyusutan dan pasien yang masih sering berobat kembali padahal berkas rekam medis tersebut sudah harus di pindahkan ke inaktif. Dengan hal tersebut maka penulis tertarik untuk mengambil judul "Tinjauan Pelaksanaan Penyusutan Berkas Rekam Medis Inaktif Di Rumah Sakit Kesehatan Jiwa Soeprapto Bengkulu".

\section{METODE PENELITIAN}

Penelitian ini dilaksanakan pada bulan januari 2016, di RSKJ Soeprapto Bengkulu. Jenis dan rancangan penelitian yang dilakukan adalah penelitian deskriptif. Menurut Notoatmodjo (2005), metode deskriptif adalah metode penelitian yang dilakukan dengan tujuan utama membuat gambaran atau deskripsi tentang suatu keadaan objektif.

Populasi dalam penelitian ini adalah 1000 berkas rekam medis inaktif di Rumah Sakit Khusus Jiwa Soeprapto Bengkulu. Menurut Notoatmodjo dalam Oktavia (2016:19), Populasi adalah sekelompok subyek atau data dengan karakteristik tertentu. Instrumen dalam penelitian ini adalah lembar observasi dan

\section{HASIL PENELITIAN}

1. Analisis Berkas Rekam Medis Inaktif yang siap disusutkan.

a.Distribusi Frekuensi Analisis Berkas

Rekam Medis yang siap disusutkan

Tabel 4.1 Analisis Berkas Rekam Medis Inaktif yang siap di susutkan di Rumah Sakit Khusus Jiwa Soeprapto Bengkulu.

\begin{tabular}{|cc|c|c}
\hline No & Keterangan & Jumlah & Persentase \\
\hline 1. & $\begin{array}{l}\text { Belum bisa disusutkan } \\
(<15 \text { Tahun })\end{array}$ & 54 BRM & $18,9 \%$ \\
\hline $2 . \quad \begin{array}{l}\text { Sudah bisa disusutkan } \\
\text { ( >15 Tahun) }\end{array}$ & 231 BRM & $81,1 \%$ \\
\hline & Jumlah & 285 BRM & $100 \%$ \\
\hline
\end{tabular}

Sumber : Data Sekunder Terolah 2016

Berdasarkan Tabel 4.1 dari 285 Berkas Rekam Medis Inaktif didapatkan Mayoritas $231(81,1 \%)$ Berkas Rekam Medis Inaktif sudah bisa disusutkan karena sudah melewati jangka waktu > 15 Tahun.

2. Pelaksanaan Prosedur Pemusnahan

Tabel 4.2

Hasil observasi Pelaksanaan Prosedur

Pemusnahan Berkas Rekam Medis Inaktif

\begin{tabular}{ll|c}
\hline No & Prosedur Pemusnahan & Hasil \\
\hline 1. & Seleksi berkas rekam medis & Terlaksana \\
\hline 2. & Pembuatan daftar pertelaan & Terlaksana \\
\hline 3. & $\begin{array}{l}\text { Persiapan pembuatan berita } \\
\text { acara dan pelaksanaan } \\
\text { pemusnahan dengak saksi- } \\
\text { saksi (Tim pemusnah) }\end{array}$ & $\begin{array}{c}\text { Tidak } \\
\text { Terlaksana }\end{array}$ \\
\hline 4. & $\begin{array}{l}\text { SOP penyusutan dan } \\
\text { Pemusnahan }\end{array}$ & $\begin{array}{c}\text { Tidak } \\
\text { Terlaksana }\end{array}$ \\
\hline
\end{tabular}

Sumber : Data Sekunder Terolah 
Dari tabel 4.2 diatas didapatkan bahwa pelaksanaan prosedur pemusnahan berkas rekam medis inaktif belum sesuai prosedurnya.

\section{PEMBAHASAN}

1. Berkas Rekam Medis Inaktif Yang Siap Disusutkan

Berdasarkan Tabel 4.1 dari 285 Berkas Rekam Medis Inaktif didapatkan bahwa 54 $(18,9 \%)$ Berkas Rekam Medis Inaktif belum bisa disusutkan dan Mayoritas 231 (81,1\%) Berkas Rekam Medis Inaktif sudah bisa disusutkan karena sudah melewati jangka waktunya sudah lebih dari 15 Tahun yaitu disimpan aktif selam 10 tahun dan 5 tahun disimpan inaktif diruang penyimpanan inaktif sementara yang ada di Rumah Sakit Khusus Jiwa Soeprapto Bengkulu.

Hasil penelitian Deta Sectio Prihatna yang berjudul "Tinjauan Pelaksanaan Retensi DRM Non Aktif di Filling Rumah Sakit Permata Bunda Purwodadi Tahun 2015" bahwa pada Rumah Sakit Permata Bunda Purwodadi untuk berkas rekam medis yang siap di susutkan sudah sesuai teori yang ada sebagai berikut adalah berkas rekam medis inaktif untuk Umum masa berlaku nya lebih dari lima tahun, lalu disimpan sekurangkurangnya dua tahun di filling inaktif tersendiri dan siap untuk disusutkan.

Berdasarkan hasil observasi pada Rumah Sakit Khusus Jiwa Soeprapto Bengkulu untuk berkas rekam medis yang dilakukan penyusutan sudah Sesuai Teori nya bahwa pada jadwal retensi yang ada menurut Dirjen Yanmed untuk berkas rekam medis jiwa itu masa berlakunya lebih dari 10 tahun dapat di jadikan inaktif dan disimpan inaktif selama 5 tahun. Di Rumah Sakit Khusus Jiwa
Soeprapto Bengkulu tentang pelaksanaan penyusutannya sudah berjalan namun belum adanya jadwal penyusutan yang berperan sangat penting untuk mengetahui jangka waktu penyimpanan berkas rekam medis baik aktif maupun inaktif. Selama ini jadwal penyusutan dilihat berdasarkan keputusan Dirjen yanmed. Maka dari itu berkas rekam medis inaktif di Rumah Sakit Khusus Jiwa Soeprapto Bengkulu selama ini yang jangka waktu nya lebih dari 10 tahun bahkan ada yang sampai 20 tahun itu masih diruangan berkas rekam medis aktif dan baru dipindahkan sekitar bulan januari yang lalu. Setelah dilihat dari sampel 285 berkas dan didapatkan 231 berkas rekam medis inaktif yang siap disusutkan, dilihat dari fisiknya berkas rekam medis inaktif tidak terdapat nilai guna lagi dan bisa langsung di musnahkan karena berkas rekam medis tersebut semuanya sudah rusak dan tidak terbaca lagi .

1. Pelaksanaan Prosedur Pemusnahan a.Seleksi, untuk memastikan lembar-lembar yang akan dimusnahkan

Di Rumah Sakit Khusus Jiwa Soeprapto Bengkulu diketahui bahwa sebelum dilakukannya pemusnahan terlebih dahulu dilakukan penilaian lembar rekam medis yang masih mempunyai nilai guna untuk dipisahkan dengan lembar yang tidak mempunyai nilai guna. Untuk lembaran-lembarannya yang dinilai yaitu seperti Lembar Resume Medis, Ringkasan Masuk dan Keluar, Lembar Kematian, Catatan Perawatan, Catatan Perkembangan itu tidak dimusnahkan .

Berdasarkan hasil observasi di Rumah Sakit Khusus Jiwa Soeprapto Bengkulu 
tata cara penyeleksian lembar-lembar yang akan dimusnahkan sudah mengikuti teori Menurut Surat Edaran Dirjen Pelayanan Medik tahun 1995 No. Hk. 00.06.1.501160 tentang Petunjuk Teknis Pengadaan Formulir Rekam Medis dan Pemusnahan Arsip Rekam Medis yaitu lembaran Ringkasan Masuk dan Keluar, Resume, Lembar Operasi, Lembar Persetujuan, Lembar Kematian.

Tetapi didapatkan bahwa dari 231 berkas rekam medis inaktif yang sudah siap disusutkan tersebut tidak terdapat nilai guna lagi karena berkas rekam medis tersebut dilihat dari segi fisiknya pun tidak memadai, tidak terbaca serta berkas sudah berjamuran dan lengket sehingga berkas rekam medis tersebut sudah bisa langsung dimusnahkan sehingga tim penilai seleksi berkas rekam medis inaktif tersebut tidak perlu menilai guna lagi. Hal ini berakibat jika tidak dilakukan penilaian berkas rekam medis ketika berkas yang bernilai guna tinggi tersebut langsung dimusnahkan, maka akan berdampak ketika pasien atau pihak lain yang masih berkepentingan dengan lembar-lembar yang tidak seharusnya dimusnahkan bisa saja pasien atau pihak itu menuntut.

Diperkuat oleh hasil penelitian orang lain oleh Kartono yang berjudul "Pemusnahan Berkas Rekam Medis Inaktif di Rumah Sakit Panti Rini Kalasan" diketahui bahwa lembar bernilai guna yang dipilah dan disimpan adalah ringkasan masuk dan keluar, resume, laporan operasi, lembar persetujuan, identifikasi bayi lahir, dan lembar kematian.
Solusi dari peneliti yaitu sebaiknya untuk Rumah Sakit Khusus Jiwa Soeprapto Bengkulu untuk penyeleksian lembarlembar berkas rekam medis inaktif lebih di perhatikan supaya sewaktu-waktu tidak terjadi kesalahan ternyata berkas rekam medis masih masih terdapat nilai guna .

b.Pembuatan daftar jenis arsip yang siap dimusnahkan

Salah satu persiapan pemusnahan adalah pembuatan Daftar pertelaan atau daftar jenis arsip yang siap dimusnahkan, didapatkan item-item dalam form pertelaan di Rumah Sakit Khusus Jiwa Soeprapto Bengkulu yaitu memuat : nomor, nomor rekam medis, tahun kunjungan terakhir, jangka waktu, kode diagnosa akhir.

Berdasarkan hasil lembar cheklist observasi di Rumah Sakit Khusus Jiwa Soeprapto Bengkulu telah terdapatnya daftar pertelaan, untuk item-item nya sudah sesuai teori nya yang ada seperti nomor rekam medis di isi nomor berkas rekam medis inaktif yang siap dimusnahkan, kemudian tahun kunjungan terakhir dilihat dari cover berkas rekam medis inaktif yang di bulatkan setelah dilakukan pemilahan dari aktif ke inaktif, dan untuk menentukan jangka waktu itu di isi berdasarkan perhitungan tahun kunjungan terakhir sampai tahun sekarang untuk menghitung apakah berkas rekam medis inaktif tersebut sudah lebih dari 15 tahun atau kurang dari 15 tahun, tetapi untuk kode diagnosa akhir di teori nya bukan kode diagnosis yang ditulis tetapi Diagnosa akhir pasien berobat. Di Rumah Sakit Khusus Jiwa Soeprapto Bengkulu Dokter menulis kode 
diagnosa akhir nya saja karena diagnosa nya hanya seperti itu saja misalnya kode diagnosis akhirnya yaitu F20, F23, d1l. Sehingga untuk kode diagnosis terkadang tidak terdapat di berkas rekam medis tersebut.

Pengendalian daftar pertelaan tersebut di ganti dari kode diagnosa akhir menjadi Diagnosa akhir pasien berobat walaupun pasien jiwa kode nya hanya itu saja , tetapi jika menulis diagnosa akhir nya itu akan lebih spesifik dan mudah di pahami.

c.Persiapan Pembuatan Berita Acara Pemusnahan Dan Pelaksanaan Pemusnahan Dengan Saksi-Saksi

Di Rumah Sakit Khusus Jiwa Soeprapto Bengkulu dalam Standar Operasional Prosedur yang ada bahwa Tim Pemusnah dibentuk dengan SK Direktur dan pembuatan berita acara pemusnahan yang ditandatangani oleh ketua dan diketahui Rumah Sakit. Dalam teori Dirjen Yanmed Berita acara tersebut berisikan item seperti hari tanggal bulan tahun, dengan cara apa dilakukan pemusnahan, jumlah berkas yang dimusnahkan (secara terlampir) kemudian tanda tangan saksisaksi dan tim ketua pelaksanaan pemusnahan dan Tim pemusnahan menurut teorinya yaitu Komite medis sebagai ketua, kepala rekam medis sebagai sekretarisnya, dengan beranggotakan petugas filling, petugas rekam medis yang terkait, serta tenaga medis lainnya, seperti perawat senior.

Dalam pelaksanaan pemusnahan berkas rekam medis inaktif tersebut telah direncanakan bahwa pemusnahan dilakukan dengan cara pembakaran biasa, dimana berkas rekam medis inaktif di bakar sampai habis dan sampai tidak dikenali baik secara isi maupun fisiknya. Berdasarkan hasil observasi di Rumah Sakit Khusus Jiwa Soeprapto Bengkulu pada pelaksanaannya belum di bentuk tim pemusnahan dan pembuatan berita acara pemusnahan, padahal untuk melakukan prosedur pelaksanaan pemusnahan salah satu syarat terpentingnya adalah pembentukan tim pemusnahan dan pembuatan form berita acara pemusnahan, Dalam pelaksanaan pemusnahan berkas rekam medis inaktif perlu adanya saksi-saksi dan pembuatan berita acara pemusnahan bahwa Rumah Sakit Khusus Jiwa Soeprapto Bengkulu akan melakukan pemusnahan sehingga dikemudian hari jika adanya kesalahan atau sebagaimana pemusnahan dilaksanakan secara resmi dengan dibentuknya tim pemusnah sesuai SK Direktur yang ada terdapat tanda bukti bahwa telah dilakukannya pemusnahan berkas rekam medis tersebut.

Dari hasil penelitian Kartono yang berjudul "Pemusnahan Berkas Rekam Medis Inaktif di Rumah Sakit Panti Rini Kalasan" bahwa belum adanya berita acara pemusnahan dan masih dalam tahap persiapan sebelum dilakukan nya pemusnahan berkas rekam medis inaktif. Diharapkan Rumah Sakit Khusus Jiwa Soeprapto Bengkulu membentuk panitia tim-tim serta pembuatan berita acara pemusnahan sebelum dilakukan pemusnahan karena dalam prosedurnya itu adalah salah satu tata cara dalam melaksanakan pemusnahan.

d.SOP Penyusutan Rekam Medis Inaktif dan SOP Pemusnahan 
Dalam penyusutan rekam medis inaktif, di Rumah Sakit Khusus Jiwa Soeprapto Bengkulu telah mempunyai Prosedur penyusutan dan pemusnahan.

Dari hasil observasi didapati bahwa SOP(Standar Operasional Prosedur) untuk penyusutan berkas rekam medis inaktif di Rumah Sakit Khusus Jiwa Soeprapto Bengkulu sudah ada. SOP(Standar Operasional Prosedur) untuk penyusutan tersebut yaitu, prosedur pemindahan dan pemilahan berkas rekam medis inaktif, prosedur penilaian berkas rekam medis inaktif, serta prosedur pemusnahan berkas rekam medis inaktif. SOP tentang pemindahan dan pemilahan berkas rekam medis inaktif berisi tentang : Mencatat nomor-nomor rekam medis yang sudah waktunya dilakukan retensi sesuai dengan ketentuan jadwal retensi, Menulis pada tracer dengan keterangan bahwa dokumen rekam medis tersebut disimpan inaktif, dan Menyelipkan tracer pada dokumen rekam medis yang disimpan. SOP Pemusnahan berkas rekam medis inaktif berisi tentang pemusnahan untuk semua berkas rekam medis yang sudah melewati batasnya yang telah ditetapkan. Menurut surat edaran Dirjen Yanmed No.HK.00.6.1.5.01160, Penyusutan berkas rekam medis yaitu pemilahan, pemindahan penilaian, dan pemusnahan. Bila dilihat dari SOP di Rumah Sakit Khusus Jiwa Soeprapto Bengkulu sudah hampir sama dengan Surat Edaran Dirjen Yanmed. Namun SOP di Rumah Sakit Khusus Jiwa Soeprapto Bengkulu dikatakan belum lengkap, karena belum ada nya Prosedur Penilaian berkas rekam medis inaktif.

Diharapkan Rumah Sakit Khusus Jiwa Soeprapto Bengkulu dapat merivisi SOP
(Standar Operasional Prosedur) agar dapat menambah prosedur penilaian berkas rekam medis inaktif guna untuk menilai guna formulir-formulir yang bernilai guna tinggi.

\section{SIMPULAN}

Dari hasil yang ada dan berdasarkan pembahasan di atas maka dapat disimpulkan bahwa :

1. Hasil analisis berkas rekam medis inaktif yang siap disusutkan didapatkan bahwa 54 $(18,9 \%)$ Berkas Rekam Medis Inaktif belum bisa disusutkan dan Mayoritas 231 (81,1\%) Berkas Rekam Medis Inaktif sudah bisa disusutkan.

2. Pelaksanaan prosedur pemusnahan sudah dilakukan tetapi belum sesuai prosedur karena tata cara nya belum terlaksana semua ,sudah dilakukan seleksi lembar-lembar berkas rekam medis, sudah adanya daftar pertelaan walaupun dalam item diagnosa akhir diganti menjadi kode diagnosa akhir, belum terdapatnya berita acara pemusnahan serta saksi-saksi atau Tim penilai berdasarkan Standar Operasional Prosedur (SK.Direktur) Rumah Sakit Khusus Jiwa Soeprapto Bengkulu.

\section{SARAN}

Berdasarkan hasil penelitian yang di dapat serta kesimpulan yang ada maka penulis mengemukakan saran sebagai berikut :

1. Untuk Rumah Sakit

a.SOP penyusutan rekam medis inaktif agar segera dilengkapi prosedur penilaian berkas rekam medis inaktifnya dan perlu di revisi.

b.Agar tersedia nya jadwal penyusutan berdasarkan Dirjen Yanmed untuk memudahkan dalam menentukan jangka waktu penyusutan. 
c. Agar Rumah Sakit Khusus Jiwa Soeprapto Bengkulu merevisi daftar pertelaan dari item kode diagnosa akhir menjadi diagnosa akhir.

d. Agar pelaksanaan penilaian rekam medis inaktif secara menyeluruh baik dalam nilai primer (ALFRED) dan nilai Sekunder.

e. Segera dilakukan pelaksanaan pemusnahan rekam medis yang telah $\mathrm{d}^{*}{ }_{36} \mathrm{n}$ penilaian akhir agar tetap menja $\mathrm{u}$ pelayanan, mengurangi jumlah BRM yang semakin bertambah, menyelamatkan BRM yang bernilai tinggi serta mengurangi yang tidak bernilai guna atau nilai gunanya turun.

2. Untuk Akkes Sapta Bakti Bengkulu

Dapat meningkatkan kemampuan mahasiswa pada laboratorium manual dan saat praktek di rumah sakit agar dapat mencontoh kegiatan pengelolaan RM yang memenuhi standar.

3. Untuk Peneliti Lainnya

Dapat mengembangkan penelitian ini dengan menggunakan variabel dan metode penelitian yang berbeda.

\section{DAFTAR PUSTAKA}

Arikunto, S. (2006). Prosedur Penelitian Suatu Pendekatan Praktik. Jakarta: Rineka Cipta.

Budi, SC. (2011). Manajemen Unit Kerja Rekam Medis. Yogyakarta: Quantum Sinergis Media.

Departemen Kesehatan Republik Indonesia. (2006). Pedoman Pengelolahan Rekam Medis Rumah Sakit Di Indonesia. Jakarta: Depkes RI.

Departemen Kesehatan Republik Indonesia. (1997). Surat Edaran Dirjen Yanmed No. Hk. 00.06.1.501160 Tentang Petunjuk Teknis
Pengadaan Formulir Rekam Medis dan Pemusnahan Arsip Rekam Medis di Rumah Sakit. Jakarta: Departemen Kesehatan RI.

Huffman, Edna K. (1994). Health Information Manajemen ; Edisi 10. Berwyn Illinois; Physician Record Company.

Meimoniesha, I. (2016). Tinjauan Pelaksanaan Retensi Dokumen Rekam Medis Nonaktif Menurut Kebijakan Akreditasi di RSUD Ambarawa.

Menkes RI. (2013). Permenkes RI Nomor 55 Tentang Penyelenggaraan Pekerjaan Perekam Medis. Jakarta: Menkes RI.

Notoatdmodjo, S. (2005). Metopen Kesehatan. Jakarta: Rineka Cipta.

Notoatdmodjo, S. (2010) Metedologi Penelitian Kesehatan

Rahayu, D. (2012). Tinjauan Pelaksanaan Penyusutan Berkas Rekam Medis Inaktif di Siloam Hospital Kebon Jerok. Jakarta: KTI, D-III RMIK.

Saraswati, D. (2015). Tinjauan Pelaksanaan Retensi Dokumen Rekam Medis Aktif di Bagian Filling Rumah Sakit Bhakti Wira Tamtama Semarang.

Undang-undang Republik Indonesia Nomor 44 Tahun 2009 Tentang Rumah Sakit.

Yanmed, Dirjen. (2006). Pedoman Penyelenggaraan dan Prosedur Rekam Medis Rumah Sakit di Indonesia. Revisi I. Jakarta. 